\title{
Hepatic Uptake of a Modified Low Molecular Weight Heparin in Rats
}

\author{
Gerd Stehle, * Eckhard A. Friedrich, ${ }^{*}$ Hannsjörg Sinn, ${ }^{*}$ Andreas Wunder, ${ }^{\star}$ Job Harenberg, * \\ Carl Erik Dempfle, * Wolfgang Maier-Borst, ${ }^{*}$ and Dieter Ludwig Heene* \\ * First Department of Medicine, Faculty for Clinical Medicine Mannheim, University of Heidelberg, W-6800 Mannheim 1, Germany; \\ and ${ }^{\ddagger}$ Department of Radiochemistry and Radiopharmacology, German Cancer Research Center, W-6900 Heidelberg, Germany
}

\begin{abstract}
Fractionated and unfractionated heparins are widely used as antithrombotic agents. Because of their heterogeneous composition, it is difficult to study the pharmacokinetics of these drugs. We now report on a new method for labeling low molecular weight heparins with ${ }^{131}$ I by binding tyramine to the anhydromannose end of the molecules. We examined the pharmacokinetics of the compound by intravenous injection of ${ }^{131} \mathrm{I}$-tyramine-heparin into Wistar rats. About $18 \%$ of the activity was found in the liver, whereas $33 \%$ was detected in urine. Biological activity in terms of Factor $\mathrm{Xa}$ inhibition was measurable. Since evidence from cell culture experiments implies that reticuloendothelial cell system receptors might be involved in heparin metabolism, maleylated BSA, a substance known to block scavenger receptors, was injected before the radiolabeled heparin compound. The liver uptake was reduced from 17.4 to $4.8 \%$. Injection of unfractionated heparin before tracer application caused a considerable increase in urine excretion of the tracer substance. To our knowledge, this is the first report that liver uptake of heparins is linked to scavenger receptor mediated mechanisms in vivo. This interaction of heparins with scavenger receptors might play an important role in the biology of the vessel wall. (J. Clin. Invest. 1992. 90:2110-2116.) Key words: heparin-pharmacokinetics • scavenger-receptor • tyramine-heparin $\bullet$ radioiodination
\end{abstract}

\section{Introduction}

Heparins are widely used as antithrombotic agents. However, because of their heterogeneous composition and their chemical properties, pharmacokinetic studies are difficult. Various studies have tried to clarify metabolic pathways of heparin and other sulfated glucosaminoglycans, using ${ }^{35} \mathrm{~S}$ as a tracing agent

Address correspondence to Dr. Gerd Stehle, First Department of Medicine, Faculty for Clinical Medicine Mannheim, University of Heidelberg, Theodor Kutzer Ufer, W-6800 Mannheim 1, Germany.

Received for publication $18 \mathrm{May} 1992$ and in revised form $20 \mathrm{Au}$ gust 1992.

J. Clin. Invest.

(c) The American Society for Clinical Investigation, Inc.

$0021-9738 / 92 / 11 / 2110 / 07 \quad \$ 2.00$

Volume 90, November 1992, 2110-2116
(1-3). Apart from a role of the kidneys in heparin pharmacokinetics, evidence was found for an uptake by the reticuloendothelial system of the liver, although results gathered with this technique have to be interpreted cautiously because of low specific activity and rapid desulfation of the tracer substance. The use of radioactive iodine coupled to heparin lead to an improvement in tracer quality (4). Considerable amounts of this tracer substance were detected in the liver of rabbits. To assess the role of the endothelial cells and the cells of the reticuloendothelial system (RES) ${ }^{1}$ in vitro, cell culture experiments were carried out, and they revealed an uptake and degradation of heparin by endothelial cells $(5,6)$. Bleiberg et al. (7) described uptake and internalization of heparins by mouse macrophages, mediated by an unknown receptor. Recently, Falcone described that heparin binding to the macrophage cell line RAW264.7 cells was mediated by scavenger receptors ( 8 ). We now present in vivo evidence that liver uptake of a modified low molecular weight derivative of heparin is mediated by a scavenger receptor-dependent mechanism.

\section{Methods}

Preparation of the tracer substance. Unfractionated porcine mucosa heparin (Heparin Na; Medac GmbH, Hamburg, Germany) was hydrolyzed using nitrous acid (9) and a tyramine residue coupled to the anhydromannose end of the polysaccharides by reductive amination (10). This tyramine-heparin preparation was further purified by HPLC (11). Carbon and proton nuclear magnetic resonance spectra of the tracer compound had been analyzed by Prof. Casu, (Istituto Scientifico di Chimica e Biochimica "G. Ronzoni," Milan). It was shown that $85 \%$ of the substance was $\mathrm{N}$-sulfated, and the rest was $\mathrm{N}$-acetylated heparin. $\mathrm{N}$-desulfated heparin was not detected, and might be present in $<2 \%$. The tyramine molecules were bound to the substance as the tyramine peaks shifted, compared with the control. Proton spectra revealed that one molecule of tyramine was present for every 20 disaccharide units. The mean molecular mass of tyramine-heparin was $5,800 \mathrm{D}$, with a $90 \%$ range between 3,000 and $8,000 \mathrm{D}$. Assuming a mean mol mass $\sim 600 \mathrm{D}$ for a disaccharide unit, it can be estimated that up to $50 \%$ of the molecules present were tyramine-derivatized. The anti-Factor Xa activity of the sample was $110 \mathrm{U} / \mathrm{mg}$ using the First International Standard for Low Molecular Weight Heparins as reference. The material contained $\sim 30 \%$ of high-affinity material for antithrombin

1. Abbreviations used in this paper: mal-BSA, maleylated BSA; RES, reticuloendothelial system; ROI, region of interest; SHPP, 3-(4-hydroxyphenyl) propionic acid $N$-hydroxysuccinimide ester. 
III. Radioactive labeling of heparin via the attached tyramine residue offers advantages compared with the conventional labeling procedures using 3-(4-hydroxyphenyl) propionic acid $N$-hydroxysuccinimide ester (SHPP), since tyramine residues are firmly linked by $\mathrm{H}_{2} \mathrm{C}-\mathrm{N}$ bridges at a defined binding site at the anhydromannose end of about $50 \%$ of the heparin molecules, whereas with the SHPP procedure, the peptide bonds of the substituents branch off from various undefined amino groups present on $\sim 8 \%$ of the molecules. The $\mathrm{H}_{2} \mathrm{C}-\mathrm{N}$ bridges are not cleaved by endogenous proteases, while the peptide bonds of the SHPP technique are $(4,10,12,13)$. For radioiodination of the modified heparin, we used a technique employing $N$-bromosuccinimide as an oxidizing agent. The detailed procedures for radioiodination have been described by Sinn et al. (13). An additional advantage of the new technique is the lower oxidation potential compared with the conventionally used chloramine $T$ procedure (14), which reduces the risk of unwanted oxidation of the compounds (13). Tracer chromatography after the labeling procedure showed one peak containing 95$98 \%$ of the radioactivity bound to tyramine-heparin, $2-5 \%$ were identified as free iodine, and as iodine bound to trace amounts of tyramine. The introduction of iodine did not alter the anticoagulant properties of the substance. Approximately half of the available tyramine residues was radiolabeled. Maleylated BSA serum (mal-BSA) was prepared by maleylating BSA with maleic acid anhydride. About 50 out of 59 lysine residues of the albumin were maleylated (15).

Animals. 15 healthy female Wistar rats weighing 250-300 g were used. They were obtained from Zentrale Tierversuchsanstalt (Hannover, Germany). The rats were kept under standard living conditions, fed a standard diet, and had free access to water. The animal experiments were approved by the German Federal Government.

Gamma camera and data evaluation. All animals were placed on a multihole collimator ( $420 \mathrm{keV})$ of a 10-in. gamma camera. For the on-line evaluation of the data, a computer system (Gaede Medworker, Gaede GmbH, Freiburg, Germany) was especially adapted to the gamma camera. To study the distribution of the tracer substance in the animals, kinetic images were registered at 2-min intervals for $60 \mathrm{~min}$. After $180 \mathrm{~min}$, a final 5-min image was recorded. The regions of interest ( $\mathrm{ROI}$ ) were marked, and the content of radioactivity in the thyroid gland, heart, liver, kidneys, and urinary bladder was evaluated. The percentage of activity present in each region of interest was calculated from the counts of that area in relation to the whole body count. A color scale from red followed by yellow, green, and blue, with decreasing amount of radioactivity, was used to visualize the data.

Animal experiments. Throughout the experiments, the rats were anaesthetized by a mixture of halothane, $\mathrm{N}_{2} \mathrm{O}$, and $\mathrm{O}_{2}(1.2 \% / 60 \% /$ $38 \%)$. The animals received $3.7 \mathrm{MBq}(100 \mu \mathrm{Ci})$ of ${ }^{131}$ I-tyramine-heparin containing $100 \mu \mathrm{g}(340-400 \mu \mathrm{g}$ of tyramine-heparin $/ \mathrm{kg}$ body wt $)$ of the substance. The tracer was administered by an intravenous injection into a lateral tail vein. $5,10,20,40,60$, and $180 \mathrm{~min}$ after tracer application, blood samples were drawn by cutting the tail tip, and after discarding the first drop of blood, $90 \mu \mathrm{l}$ of whole blood was collected and mixed with $10 \mu \mathrm{l}$ of sodium citrate in a siliconized glass capillary. Anti-Factor Xa activity was measured by a coagulometric method (Heparimat ${ }^{\star}$ Test; Bio Merieux, Paris, France) using a KC4 coagulometer (KC4; Amelung Lemgo, Germany), as described previously (16). The normal range of this test in the untreated rat was determined to be between 12 and $15 \mathrm{~s}$. An additional $10 \mu \mathrm{l}$ of blood was collected for radioactivity measurement. A reference curve was prepared using serial dilutions of the tracer substance. The equation blood vol $=0.06$ $X$ body wt +0.77 (17) was used to estimate the blood volume of the animal. From these data, the percentage of the applied radioactivity present in the blood at different times was calculated. The blood loss of the animals was $<2 \mathrm{ml}$ or $<10 \%$ of the respective total blood volume. A catheter was placed in the urinary bladder for analysis of the tracer composition in urine. The amount of urine excreted was continuously monitored. The radioactivity was determined in all samples at 15 -min intervals for $60 \mathrm{~min}$. Fractions of these samples were assayed by thin layer chromatography to assess tracer stability. After the final measure- ment and blood sampling ( $180 \mathrm{~min}$ ), the animals were killed and their organs were removed. Aliquots of the organs were taken and after determination of the weight, the radioactivity of the samples was measured in a gamma counter. The specific activity per gram of tissue was calculated, and multiplied with the weight of the respective organs. The results were expressed as percent of radioactivity applied to the animal initially. The following organs were examined: liver, kidneys, spleen, thymus, lungs, stomach, intestines, colon, muscle, and the thyroid gland.

Three groups were formed for the study, and all animals were randomly distributed. Group 1 (mal-BSA) received $2 \mathrm{mg}$ of mal-BSA 2 min before tracer application to block the scavenger receptor of the RES cells. Group 2 ( heparin competition) received $2 \mathrm{mg}$ of unfractionated heparin to compete with the tracer substance for binding sites. Group 3 (control) received only the tracer substance.

\section{Results}

Five female Wistar rats received $100 \mu \mathrm{g}$ of ${ }^{131} \mathrm{I}$-tyramine-heparin (3.7 MBq $=100 \mu \mathrm{Ci}, 11$ anti-Xa units) by an intravenous injection. Another five animals received $2 \mathrm{mg}$ of mal-BSA to block scavenger receptors of cells 2 min before the tracer substance. To provide further information on the behavior of the tracer substance, five rats were preinjected with $2 \mathrm{mg}$ of unfractionated heparin to compete for binding sites. Blood samples of all animals were assayed for anti-Factor Xa activity (Heparimat ${ }^{\oplus}$ test system; normal range $12-15 \mathrm{~s}$ for untreated rats). A considerable prolongation of the clotting time was seen for the mal-BSA group and the control confirming the anticoagulant properties of the tracer substance in vivo (Fig. 1). The clotting time of the control group after 5 min was prolonged to a mean of $53 \mathrm{~s}$, whereas the mal-BSA pretreated animals had a considerably higher value $(80 \mathrm{~s})$. These differences prevailed throughout the study period of $180 \mathrm{~min}$. After $3 \mathrm{~h}$, clotting times were still prolonged with $24.5 \mathrm{~s}$ for the control group and $32.7 \mathrm{~s}$ for the mal-BSA group, respectively. The clotting times for the heparin competition group were above the measuring range of

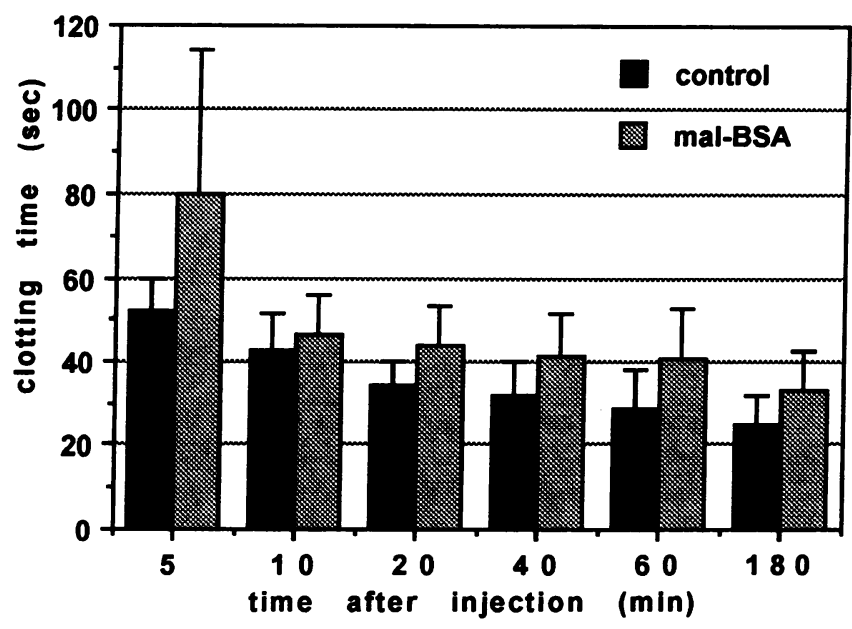

Figure 1. Anti-Factor Xa activity (in seconds) after injection of 100 $\mu \mathrm{g}{ }^{131}$ I-tyramine-heparin $(3.7 \mathrm{MBq}=100 \mu \mathrm{Ci})$. The control group received ${ }^{131} \mathrm{I}$-tyramine-heparin alone, whereas the mal-BSA group received the tracer 2 min after the application of $2 \mathrm{mg}$ of mal-BSA. The mean values and SD of the control, and the mal-BSA group are shown $(n=5)$. 


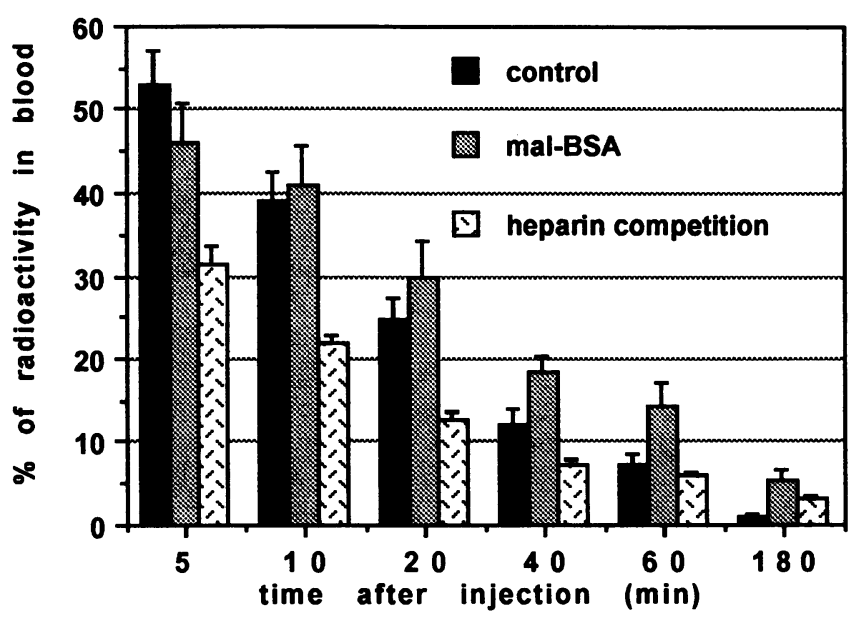

Figure 2. Percentage of radioactivity present in blood after the injection of $100 \mu \mathrm{g}{ }^{131}$ I-tyramine-heparin $(3.7 \mathrm{MBq}=100 \mu \mathrm{Ci})$. The percentage is calculated on basis of the applied amount of radioactivity. The control group received ${ }^{131}$ I-tyramine-heparin alone, whereas the mal-BSA group received the tracer $2 \mathrm{~min}$ after the application of $2 \mathrm{mg}$ of mal-BSA. The heparin competition group was preinjected $2 \mathrm{mg}$ of unfractionated heparin followed by tracer application 2 min later. The mean values and SD are shown $(n=5)$.

the coagulation test ( $>180 \mathrm{~s}$ ) throughout the experiment and are therefore not shown.

An analysis of the percentage of the tracer present in the blood of the control animals revealed an initial peak of $53.4 \%$ of the applied radioactivity after $5 \mathrm{~min}$, a fast decline to $25.4 \%$ after $20 \mathrm{~min}$, to $7.5 \%$ after $60 \mathrm{~min}$, and to $1 \%$ after $180 \mathrm{~min}$ (Fig. 2). The data for the mal-BSA treated animals differed from these findings. After $5 \mathrm{~min}, 46 \%$ of the tracer was measurable in the blood. After $20 \mathrm{~min}, 30 \%$ of the activity was still present in the circulation, and after $60 \mathrm{~min}$, the values were twice as high as in the control group. Five times more activity was present in the blood of the animals with blocked scavenger

Table I. Specific Activity of the Tracer $(\times 1,000 \mathrm{cpm} / \mathrm{g}$ tissue $)$ in Various Organs $180 \mathrm{~min}$ after Application of $100 \mu \mathrm{g}$ of ${ }^{131} \mathrm{I}$ Tyramine-Heparin $(3.7 \mathrm{MBq}=100 \mu \mathrm{Ci})$, Showing the Avidity Per Gram Tissue towards the Tracer

\begin{tabular}{|c|c|c|c|c|c|c|}
\hline \multirow[b]{2}{*}{ Organ } & \multicolumn{2}{|c|}{ Mal-BSA group } & \multicolumn{2}{|c|}{ Heparin comp. } & \multicolumn{2}{|c|}{ Control } \\
\hline & Mean & SD & Mean & SD & Mean & SD \\
\hline Liver & 120 & 8 & 71 & 16 & 419 & 58 \\
\hline Kidney & 912 & 116 & 810 & 180 & 779 & 167 \\
\hline Spleen & 489 & 25 & 35 & 4 & 252 & 26 \\
\hline Intestine & 344 & 52 & 78 & 8 & 297 & 86 \\
\hline Colon & 215 & 49 & 103 & 25 & 190 & 18 \\
\hline Stomach & 170 & 14 & 75 & 20 & 114 & 32 \\
\hline Lung & 95 & 20 & 133 & 42 & 82 & 23 \\
\hline Thymus & 78 & 14 & 33 & 4 & 49 & 2 \\
\hline Muscle & 16 & 5 & 18 & 2 & 16 & 4 \\
\hline
\end{tabular}

Before the tracer application, the animals of the mal-BSA group received an injection of $2 \mathrm{mg}$ mal-BSA. The animals in the heparin competition group received $2 \mathrm{mg}$ unfractionated heparin before tracer application instead of mal-BSA ( $n=5$ animals, mean values, and SD). receptors ( $5.5 \%$ vs $1 \%$ ) after $180 \mathrm{~min}$. In the heparin competition group, $\sim 70 \%$ of the tracer substance was removed from circulation within $5 \mathrm{~min}$. After $3 \mathrm{~h}, 3.2 \%$ of the initially applied activity was measured, giving a value between the mal-BSA group and the control. The SD was $<10 \%$ of the respective mean values, supporting the reliability of the data and the differences recorded.

After $180 \mathrm{~min}$ the animals were killed and their organs were removed. Table I displays the specific activity of the organs; i.e., the amount of counts per gram of tissue. The data show the capacity of tissues to accumulate the tracer substance, but do not reflect the importance of the whole organs in metabolizing the tracer. The highest specific activity was found in the kidneys with mean values of $779,000 \mathrm{cpm} / \mathrm{g}$ in the control group and $810,000 \mathrm{cpm} / \mathrm{g}$ in the heparin competition group vs $912,000 \mathrm{cpm} / \mathrm{g}$ in the mal-BSA group. Ranking second in the control group was the liver with $419,000 \mathrm{cpm} / \mathrm{g}$. Because of the blocking of the scavenger receptors, this value was reduced to $120,000 \mathrm{cpm} / \mathrm{g}$ in the mal-BSA group. In the competition experiment with unfractionated heparin, the uptake of the radioactive material by the liver was further diminished to only $71,000 \mathrm{cpm} / \mathrm{g}$, implying additional non-mal-BSA blockable binding. The spleen, ranking fourth in the control group with $252,000 \mathrm{cpm} / \mathrm{g}$, ranked second after blocking with mal-BSA with $489,000 \mathrm{cpm} / \mathrm{g}$, suggesting alternative binding sites that are not blocked by mal-BSA, but by unfractionated heparin $(35,000 \mathrm{cpm} / \mathrm{g})$. The tissues of the gastrointestinal tract showed no significant differences after mal-BSA application, but preinjected unfractionated heparin significantly lowered the tracer binding of stomach, small intestines, and colon. The content of radioactivity of the other organs seemed to be not decisively altered. The muscle samples taken showed the lowest specific activities measured.

To assess the share of the organs on the metabolism of the substance, it was necessary to check the total amount of activity per organ (Fig. 3, Table II). In Fig. 3, the percentage of radioactivity at the time of organ removal and the percentage of activity in blood and excreted into urine are shown to indi-

Table II. Amount of Radioactivity in Various Organs $180 \mathrm{~min}$ after Application of $100 \mu \mathrm{g}$ of ${ }^{131}$ I-Tyramine-Heparin $(3.7 \mathrm{MBq}=100 \mu \mathrm{Ci})$

\begin{tabular}{lcccccccc}
\hline & \multicolumn{2}{c}{ Mal-BSA group } & & \multicolumn{2}{c}{ Heparin comp. } & & \multicolumn{2}{c}{ Control } \\
\cline { 2 - 3 } Organ & Mean & SD & & Mean & SD & & Mean & SD \\
\hline Liver & 4.77 & 0.23 & & 2.31 & 0.21 & & 17.36 & 1.09 \\
Kidney & 8.51 & 0.69 & & 6.12 & 0.86 & & 6.82 & 0.50 \\
Stomach & 1.05 & 0.08 & & 0.43 & 0.11 & & 0.73 & 0.22 \\
Spleen & 0.96 & 0.32 & & 0.10 & 0.03 & & 0.44 & 0.03 \\
Lung & 0.59 & 0.13 & & 0.84 & 0.27 & & 0.43 & 0.13 \\
Thyroid & 0.15 & 0.07 & & 0.11 & 0.02 & & 0.24 & 0.14 \\
Thymus & 0.05 & 0.01 & & 0.04 & 0.01 & & 0.04 & 0.01
\end{tabular}

Percentages calculated from the originally administered amount. The control group received ${ }^{131} \mathrm{I}$-tyramine-heparin. The mal-BSA group received $2 \mathrm{mg}$ mal-BSA $2 \mathrm{~min}$ before tracer application. The animals in the heparin competition group received $2 \mathrm{mg}$ unfractionated heparin before tracer application instead of mal-BSA ( $n=5$ rats, mean values and $\mathrm{SD}$ ). 


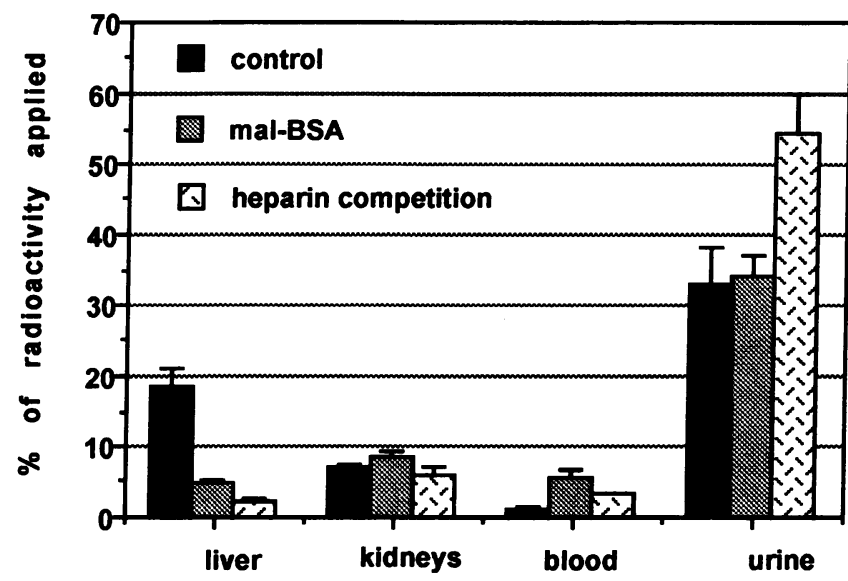

Figure 3. Percentage of radioactivity found in the liver, kidneys, blood, and urine $3 \mathrm{~h}$ after the injection of $100 \mu \mathrm{g}{ }^{131} \mathrm{I}$-tyramine-heparin $(3.7 \mathrm{MBq}=100 \mu \mathrm{Ci})$. The percentage is calculated on basis of the applied amount of radioactivity. The control group received ${ }^{131}$ I-tyramine-heparin alone, whereas the mal-BSA group received the tracer $2 \mathrm{~min}$ after the application of $2 \mathrm{mg}$ of mal-BSA. The heparin competition group was preinjected $2 \mathrm{mg}$ of unfractionated heparin followed by tracer application 2 min later. The mean values and SD are shown $(n=5)$.

cate the tracer balance of the examined organ systems. In the control animals the liver accounted for $17.4 \%$ of the radioactivity, ranking well above the kidneys with a total of $6.8 \%$ of the activity. After treatment with mal-BSA only $4.8 \%$ of the applied activity was present in the liver after $180 \mathrm{~min}$. The tracer uptake of the liver was diminished to $2.3 \%$ in the heparin competition group. These data disclose the importance of the cells of the liver RES in the uptake of the heparin tracer. The amount of radioactivity found in the kidneys was $8.5 \%$, illustrating the increasing share of the kidneys in heparin pharmacokinetics after blocking the hepatic uptake. In spite of the high specific activity, the spleen contributed to $<0.5 \%$ to the radioactivity measured in the control group vs $1 \%$ in the mal-BSA group. Like in other organs the tracer substance was almost completely displaced from the spleen $(0.1 \%)$ by unfractionated heparin. Only $0.11,0.15$, and $0.24 \%$ of the applied activity was found in the thyroid gland, denoting the in vivo stability of the tracer substance.

To gain further knowledge on the fate of the tracer substance, the different kinetics of accumulation or disappearance in the organs were monitored by whole body scintigraphy. ROIs were defined for the liver, the kidneys, and the urinary bladder. The percentages stated in the scintigraphic figures are not fully comparable numerically to the percentages, calculated from the removed organs on a basis of absolute values, since the scintigraphic data reflect areas and not whole organs. As expected, similar effects were visible on a relative basis. With the decreasing role of the liver ROI after mal-BSA blocking or competition by unfractionated heparin, the increasing role of the kidneys and of the urine excretion in the pharmacokinetics of the substance was obvious (Figs. 3 and 4, $A$ and $B$ ). The liver region is clearly visible on the scintigrams recorded after $180 \mathrm{~min}$ for the control group (Fig. $5 \mathrm{~A}$ ). In the animals of the mal-BSA group, the radioactivity registered over the liver region is depressed, whereas the radioactivity measured over the kidneys is considerably enhanced (Fig. $5 B$ ). From these scintigraphic data, it was possible to calculate that within $3 \mathrm{~h}$, $55 \pm 5.6 \%$ of the initially administered dosage was excreted in urine among the animals of the heparin competition group, whereas urinary excretion in the mal-BSA group and the control group was $\sim 20 \%$ lower (Fig. 3).

To receive additional information on tracer stability in vivo, urine was collected from animals of the control group by a catheter. About $25 \%$ of the amount of radioactivity injected intravenously was recovered within $30 \mathrm{~min}$. An additional 2-6\% was found during the next $30 \mathrm{~min}$. Tracer chromatography revealed that the major amount of the tracer compound was chemically intact in urine and consisted of $93-98 \%{ }^{131} \mathrm{I}-\mathrm{ty}-$
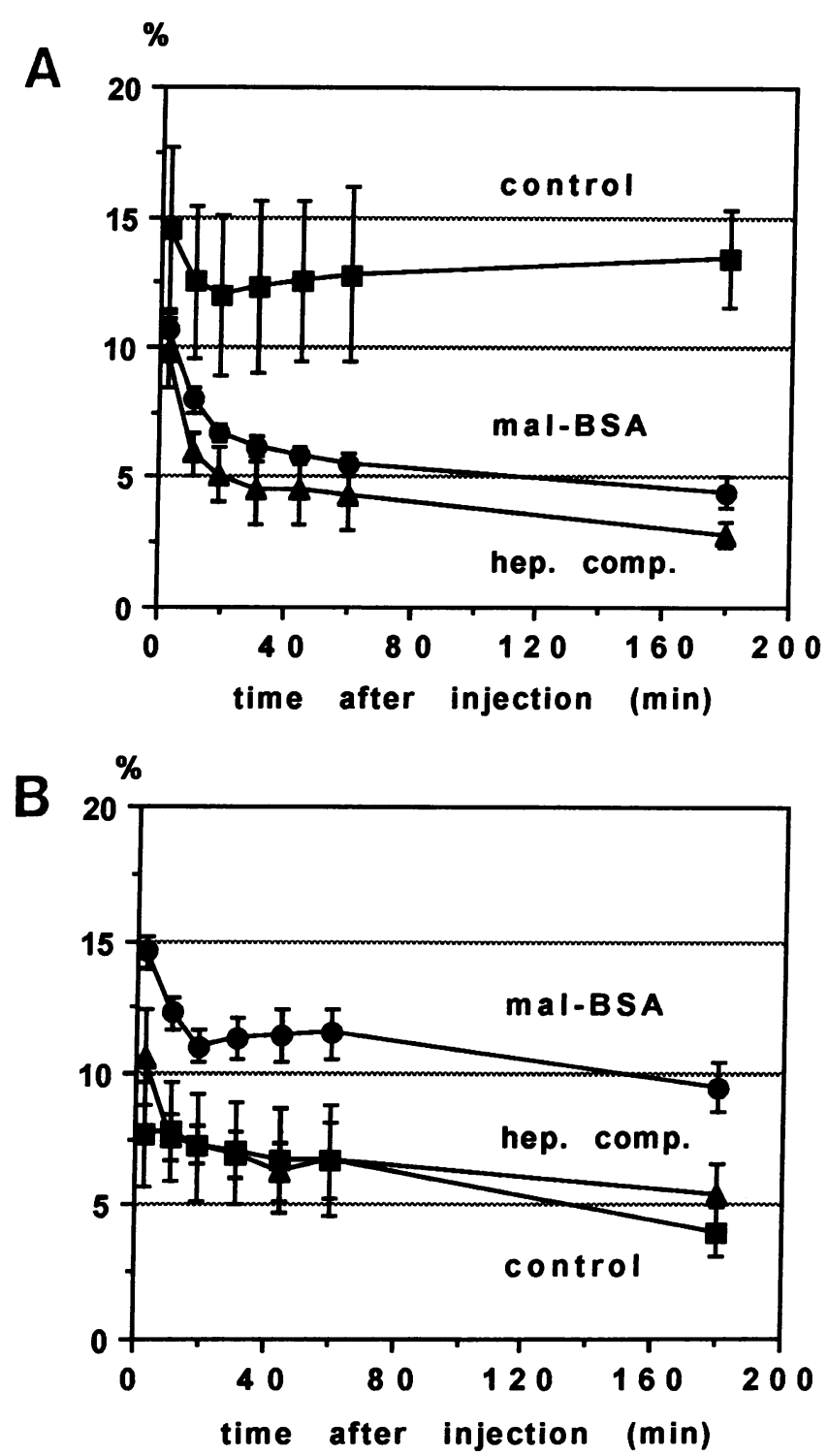

Figure 4. The kinetics of influx and efflux of $100 \mu \mathrm{g}$

${ }^{131}$ I-tyramine-heparin tracer $(3.7 \mathrm{MBq}=100 \mu \mathrm{Ci})$ over the ROIs of the liver $(A)$ and the kidneys $(B)$, as registrated by scintigraphy. The control group received ${ }^{131} \mathrm{I}$-tyramine-heparin alone, whereas the malBSA group received the tracer $2 \mathrm{~min}$ after the application of $2 \mathrm{mg}$ of mal-BSA. The heparin competition group was preinjected $2 \mathrm{mg}$ of unfractionated heparin followed by tracer application $2 \mathrm{~min}$ later. The mean values and SD are shown $(n=5)$. 

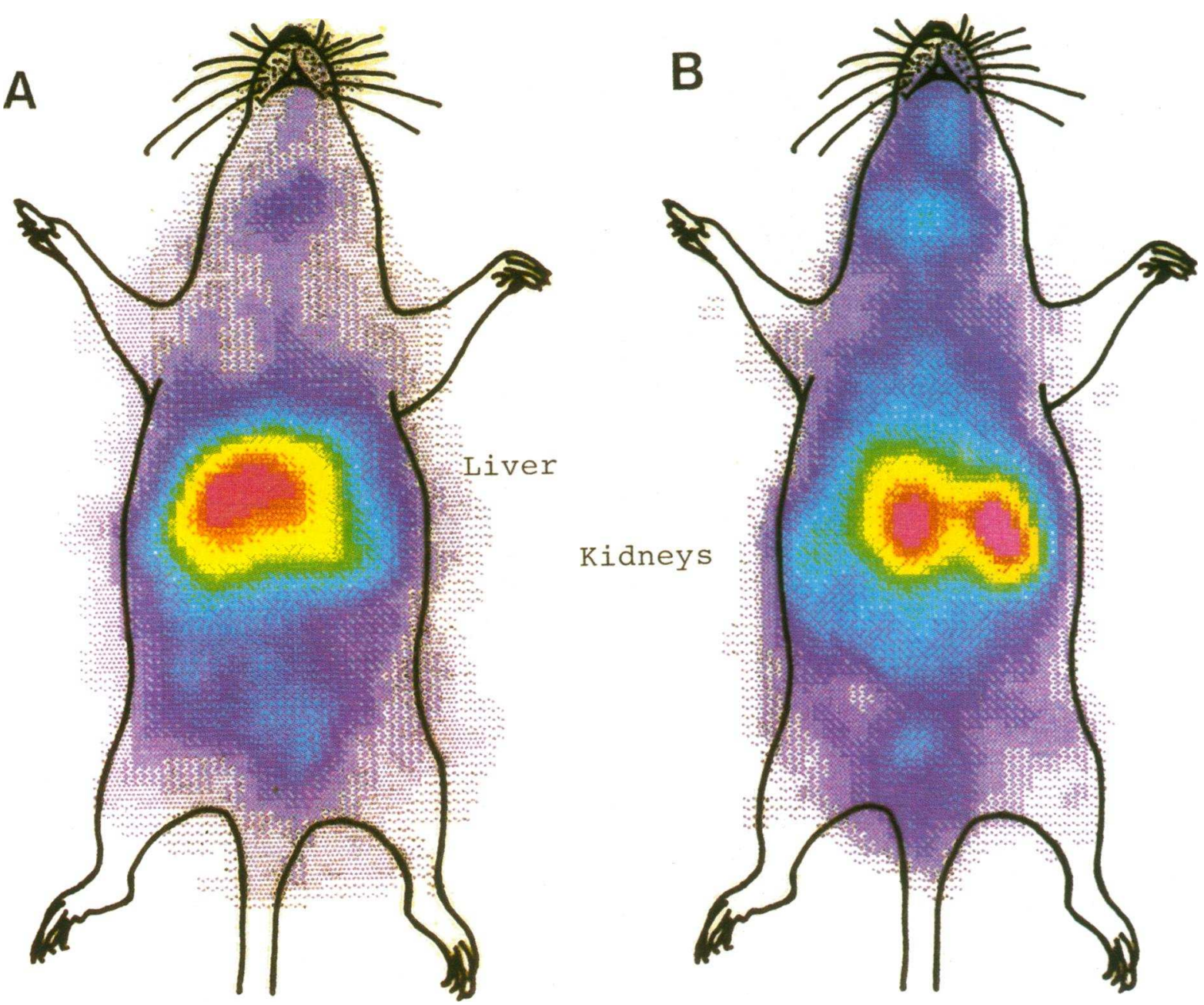

Figure 5. Scintigraphic images of a rat from the control group $(A)$ and of a rat from the mal-BSA group $(B) 180$ min after application of $100 \mu \mathrm{g}$ ${ }^{131}$ I-tyramine-heparin tracer $(3.7 \mathrm{MBq}=100 \mu \mathrm{Ci})$. The control group received ${ }^{131} \mathrm{I}$-tyramine-heparin alone. The mal-BSA group received the tracer $2 \mathrm{~min}$ after the application of $2 \mathrm{mg}$ of mal-BSA.

ramine-heparin. Coagulation tests were performed with an aliquot of pooled urine, containing ${ }^{131}$ I-tyramine-heparin, showing prolonged clotting times. Only trace amounts of free ${ }^{131} I$ and of ${ }^{131} I$ coupled with tyramine were detected in urine.

\section{Discussion}

Radiopharmacokinetic studies with low molecular weight heparins showed that a considerable amount of the material is removed from the circulation within $15 \mathrm{~min}$ and can be found in urine. The hepatic uptake mechanism was blocked by malBSA, leading to an increased blood level of the tracer, whereas the rate of urinary excretion increased only slightly. In the competition experiment with unfractionated heparin, the hepatic uptake was found to be reduced (liver $2.3 \%$ ), whereas the amount of tracer substance in urine increased by $\sim 20 \%$ compared with the control and mal-BSA groups (Fig. 3).

These data support the hypothesis that the hepatic uptake of heparin depends on a receptor-mediated mechanism. Gold- stein et al. (18) found a receptor for acetylated low-density lipoproteins on cultured murine macrophages, which was named "scavenger receptor." Subsequent research on this receptor resulted in describing a major role of this receptor and the macrophages in the formation of the foam cell, the latter being a major constituent of the early atherosclerotic lesions (19). Type I and type II bovine scavenger receptors have recently been characterized in their tertiary structures $(20,21)$. At least three different kinds of scavenger receptors have been postulated, and extensive investigations have been carried out by our group throughout recent years (15, 22-24). Mal-BSA was found to be a reliable agent to detect and to characterize the different scavenger receptors in vivo and in vitro $(15,25)$.

Hiebert (26) described the uptake of heparin by liver sinusoidal cells in rabbits. Bleiberg et al. (7) postulated heparin receptors on mouse macrophages in culture. Evidence for a scavenger mediated heparin uptake in cultured macrophages was published by Falcone (8). However, like all results from 
cell culture experiments, these findings cannot easily be adopted for explanation of in vivo findings. Our data now suggest a role of scavenger receptors in heparin metabolism in vivo. By preinjecting $2 \mathrm{mg}$ of mal-BSA, it was possible to block the uptake of the heparin tracer by scavenger receptor-bearing cells almost completely for a period of $3 \mathrm{~h}$. The liver uptake of radioactivity was reduced from an average of 17.4 to $4.8 \%$ of the activity, paralleled by an increase of blood levels. Injection of unfractionated heparin as a competing agent for tracer binding prevented accumulation of the tracer substance in the liver with a mere $2.3 \%$ of activity left. Tracer binding was also reduced by competition of unfractionated heparin in the tissues of the gastrointestinal tract and in the spleen (Table I).

Thus, a scavenger receptor-mediated uptake of heparin by liver macrophages and sinusoidal endothelial cells might play an important role for the liver metabolism of both the tracer compound of low molecular weight and of unfractionated heparin. Additional non-scavenger receptor binding sites can be occupied by nonlabeled unfractionated heparin causing urinary excretion of the tracer substance to increase. It can be suspected that these unsaturated binding sites are localized on the endothelial cells of the vascular system that are under physiologic conditions devoid of scavenger receptors. This would be supported by data published from Hiebert et al. (5) and Barzu et al. (6) on the role of endothelial cells in heparin metabolism.

Thus, our pharmacokinetic data suggest that in heparin metabolism there are two saturable uptake mechanisms. One mechanism is mediated by scavenger receptor-mediated heparin uptake by the macrophage cell system, whereas the other is formed by the endothelial cell system. Saturation of both binding sites by administration of unfractionated heparin before the heparin tracer compound results in an increase in the excretion of the substance by the kidneys to urine. These results are in agreement with the results published by Boneu et al. $(27,28)$, who described these two distinct mechanisms of elimination in rabbits by studying the disappearance of ${ }^{125} \mathrm{I}-\mathrm{SHPP}$-heparin from blood.

The interaction with scavenger receptors of macrophages might be responsible for several biological properties of heparin. Stimulation of the macrophage tumor cell line RAW264.7 cells by adding heparin had been found to increase the secretion of urokinase type plasminogen activator (8). Studies carried out by Markwardt and Klöcking (29) and Vinazzer et al. (30) in perfused organ systems showed an increase in fibrinolytic activity after heparin stimulation. Studies using a rabbit jugular vein clot lysis model suggested that low molecular weight heparins exhibited dose-dependent in vivo fibrinolytic activity comparable to clinically effective doses of urokinase (31). A recent clinical trial on treatment of deep venous thrombosis with either unfractionated heparin intravenously or low molecular weight heparin subcutaneously revealed considerable recanalization rates of the occluded vessels as judged by phlebography (32), also supporting a profibrinolytic potential of heparin preparations. An effect of heparin on the metabolism of low density lipoprotein metabolism has recently been presented. A high affinity heparin subfraction (8\%) for low density lipoprotein was found to cause an accumulation of cholesteryl ester in mouse macrophages (33). Soluable heparin proteoglycans released from mast cells might induce the uptake of low density lipoproteins by macrophages via a scavenger receptor-mediated phagocytosis (34). The regulation of macrophage lipoprotein lipase secretion might also be influenced by scavenger receptor-mediated uptake of glycosaminoglycans (35). The findings could provide an additional explanation for the properties of heparins to stimulate lipoprotein lipase activity in vivo, apart from the hypothesized competition of heparin and lipoprotein lipase for binding sites on endothelial cells (36).

The interaction of heparins with scavenger receptors thus appear to play a complex and important role in the biology of the vessel wall with implications for physiological and pathological mechanisms, in which cells of the liver RES are involved.

\section{Acknowledgments}

For technical assistance, the authors thank H. H. Schrenk, R. Kühnlein, and A. Tietz. For the nuclear magnetic resonance analysis of the tyramine-heparin compound, we express our gratitude to Prof. B. Casu, G. Torri, and M. Guerrini from Istituto Scientifico di Chimica e Biochimica "G. Ronzoni," Milan.

This work was supported by grant Ste 647/1-1 from Deutsche Forschungsgemeinschaft.

\section{References}

1. Astrup, P. 1947. On the determination of heparin in blood plasma and urine. Acta Pharmacol. 3:165-178.

2. Eiber, H. B. 1957. Clearance of injected heparin from the blood. A Weekly Journal of Science. 180:1359-1360.

3. Day, M., J. P. Green, and J. D. Robinson. 1962. Disposition of [35S]heparin in the rat. Brit. J. Pharmacol. 18:625-629.

4. Dawes, J., and D. S. Pepper. 1979. Catabolism of low-dose heparin in man. Thromb. Res. 14:845-860.

5. Hiebert, L. M., and L. B. Jaques. 1976. Heparin uptake on endothelium. Artery. 2:26-37.

6. Barzu, T., J. L. M. L. van Rijn, M. Petitou, G. Tobelem, and J. P. Caen 1987. Heparin degradation in the endothelial cells. Thromb. Res. 47:601-609.

7. Bleiberg, I., I. MacGregor, and M. Aronson. 1983. Heparin receptors on mouse macrophages. Thromb. Res. 29:53-61.

8. Falcone, D. J. 1989. Heparin stimulation of plasminogen activator secretion by macrophage-like cell line RAW264.7: role of the scavenger receptor. $J$. Cell. Physiol. 140:219-226.

9. Horten, D., and K. D. Philips. 1973. The nitrous acid deamination of glycosides and acetates of 2-amino-2-desoxy-D-glucose. Carbohydr. Res. 30:367374.

10. Harenberg, J., and R. Malsch. 1992. German Patent No. P4217916.5-43.

11. Harenberg, J., and J. X. de Vries. 1983. Characterization of heparins by high performance size exclusion liquid chromatography. J. Chromatogr. 261:287-292.

12. Bolton, A. E., and W. M. Hunter. 1973. The labelling of proteins to high specific radioactivities by conjugation to a 125 -I containing acylating agent. Biochem. J. 133:529-536.

13. Sinn, H., H. H. Schrenk, E. A. Friedrich, D. P. Via, and H. A. Dresel. 1988. Radioiodination of proteins and lipoproteins using N-bromosuccinimide as oxidizing agent. Anal. Biochem. 170:186-192.

14. Greenwood, F. C., W. M. Hunter, and J. S. Glover. 1963. The preparation of 131-Iodine labelled human growth hormone of high specific activity. Biochem. J. 89:114-123.

15. Ottnad, E., P. Via, J. Frühbis, H. J. Sinn, E. A. Friedrich, R. Ziegler, and H. A. Dresel. 1992. Differentiation of binding sites on reconstituted hepatic scavenger receptors using oxidized low-density lipoprotein. Biochem. J. 281:745-751.

16. Harenberg, J., C. Giese, C. E. Dempfle, G. Stehle, and D. L. Heene. 1988 Monitoring of heparin and low molecular weight heparin with capillary and venous whole blood. Thromb. Haemostasis. 60:377-381.

17. Lee, H. B., and M. D. Blaufox. 1985. Blood volume in the rat. J. Nucl. Med. 25:72-76.

18. Goldstein, J. L., Y. K. Ho, S. K. Basu, and M. S. Brown. 1979. Binding site on macrophages that mediates uptake and degradation of acetylated low density lipoprotein, producing massive cholesterol deposition. Proc. Natl. Acad. Sci. USA. 76:333-337.

19. Witztum, J. L., and D. Steinberg. 1991. Role of oxidized low density lipoprotein in atherogenesis. J. Clin. Invest. 88:1785-1792.

20. Kodama, T., M. Freeman, L. Rohrer, J. Zabrecky, P. Matsudaira, and M. Krieger. 1990. Type I macrophage scavenger receptor contains alpha helical and collagen-like coiled coils. Nature (Lond.). 343:531-535. 
21. Rohrer, L., M. Freeman, T. Kodama, M. Penman, and M. Krieger. 1990 Coiled coil fibrous domains mediate ligand binding by macrophage scavenger receptor type II. Nature (Lond.). 343:570-572.

22. Friedrich, E. A., H. A. Dresel, H. Sinn, and G. Schettler. 1985. Visualization of the hepatic low-density lipoprotein receptor in rats by sequential scintiscans. FEBS (Fed. Eur. Biochem. Soc.) Lett. 184:134-138.

23. Dresel, H. A., E. A. Friedrich, D. P. Via, H. Sinn, R. Ziegler, and G Schettler. 1985. Binding of acetylated low density lipoprotein and maleylated bovine serum albumin to the rat liver: one or two receptors? EMBO (Eur. Mol. Biol. Organ.) J. 4:1157-1162.

24. Dresel, H. A., E. A. Friedrich, D. P. Via, G. Schettler, and H. Sinn. 1987. Characterization of binding sites for acetylated low density lipoprotein in the rat liver in vivo and in vitro. EMBO (Eur. Mol. Biol. Organ.) J. 6:319-326.

25. Ottnad, E., D. P. Via, H. Sinn, E. A. Friedrich, R. Ziegler, and H. A Dresel. 1990. Binding characteristics of reduced hepatic receptors for acetylated low density lipoprotein and maleylated bovine serum albumin. Biochem. J. 265:689-698.

26. Hiebert, L. 1981. The uptake of heparin by liver sinusoidal cells in normal and atherosclerotic rabbits. Thromb. Res. 21:383-390.

27. Boneu, B., M. R. Buchanan, C. Caranobe, A. M. Gabaig, D. Dupouy, P. Sie, and J. Hirsh. 1987. The disappearance of a low molecular weight heparin fraction (CY 216) differs from standard heparin in rabbits. Thromb. Res. 46:845853

28. Boneu, B., C. Caranobe, A. M. Gabaig, D. Dupouy, P. Sie, M. R. Buchanan, and J. Hirsh. 1987. Evidence for a saturable mechanism of disappearance of standard heparin in rabbits. Thromb. Res. 46:835-844.
29. Markwardt, F., and H. Klöcking. 1977. Heparin induced release of plasminogen activator. Haemostasis. 6:370-374.

30. Vinazzer, H., A. Stemberger, S. Haas, and G. Blümel. 1982. Influence of heparin, of different heparin fractions and low molecular weight heparin like substances on the mechanism of fibrinolysis. Thromb. Res. 27:341-352.

31. Bacher, P., D. Welzel, O. Iqbal, D. Hoppenstaedt, D. Callas, J. M. Walenga, and J. Fareed. 1992. The thrombolytic potency of LMW-heparin compared to urokinase in a rabbit jugular vein clot lysis model. Thromb. Res. 66:151158.

32. Harenberg, J., K. Huck, H. Bratsch, G. Stehle, C. E. Dempfle, K. Mall, M. Blauth, K. H. Usadel, and D. L. Heene. 1990. Therapeutic application of subcutaneous low molecular weight heparin in acute venous thrombosis. Haemostasis. 20:205-219.

33. Srinivasan, S. R., P. Vijayagopal, K. Eberle, B. Radhakrishnamurthy, and G. S. Berenson. 1991. Interaction of a high-affinity heparin subfraction with low-density lipoprotein stimulates cholesteryl ester accumulation in mouse macrophages. Biochim. Biophys. Acta. 1081:188-196.

34. Lindstedt, K. A., J. O. Kokkonen, and P. T. Kovanen. 1992. Soluable heparin proteoglycans released from stimulated mast cells induce the uptake of low density lipoproteins by macrophages via scavenger receptor mediated phagocytosis. J. Lipid Res. 33:65-75.

35. Murata, Y., S. R. Behr, and F. B. Kraemer. 1988. Regulation of macrophage lipoprotein lipase secretion by the scavenger receptor. Biochim. Biophys. Acta. 972:17-24.

36. Harenberg, J., G. Stehle, J. Augustin, and R. Zimmerman. 1989. Comparative human pharmacology of low molecular weight heparins. Semin. Thromb. Hemostasis. 15:414-423. 